\section{Preventing Collisions with Icebergs}

Although it is, I believe, ascertained that fogs are often highly athermanous, I would, at the same time, like to ask whether a thermal radiation method might not serve to show the presence of a large mass of ice in the neighbourhood of a ship. I venture to make the suggestion, as I know of no experiments on the degree of athermancy possessed by fogs, as tested by such an instrument as the bolometer of Prof. Langley. The use of this instrument, or even of the thermopile, in conjunction with a large reflector and an alarm circuit closed by galvanometer deflection, might be worth trial by any one possessing the opportunity.

Engineering School, Trinity College, Dublin, August

\section{Monkeys and Water}

Is it a usual thing for monkeys, either in captivity or in their native condition, to take freely to the water? Some relations of mine have a small monkey that was brought to them from Java, and which is a great pet. One day it was thought that he should be bathed, and he was put on the edge of the bath. In a little while he hung down from the edge by a foot and hand, and drank the water, and then, plunging in, he swam backwards and forwards under the water, with his eyes open, with great enjoyment.

After the first time he was frequently bathed, and a day or two ago I saw him go through the performance. It was very pretty to see how he enjoyed it, swimming under the water and diving away from a hand put down th take him; then going head over heels at the bottom and lying on his back to bite playfully at a finger; then he would run about on all-fours with his head held out of the water, and then go under again : and after it all, when he was taken out and dried with a towel, he lay wrapped up in a shawl, sleeping comfortable and happy. I should like to know whether he is an exception to the rule in his love of the water.

15, Avenue Road, Regent's Park, August 6

JERRY BARRETT

\section{A Correction}

I HAVE very stupidly made it appear in my note on pitcher plants, printed in last week's NATURE (p. 341), that Dr. McBride was President of the Linnean Society in 1815 . I ought to have written, "In I8I5 the then President of the Linnean Society read a communication from Dr. James McBride," \&c. I suppose Sir James Edward Smith was at that time President of the Linnean Society, and that Dr. McBride never was.

Angust 15

\section{A MODEL UNIVERSITY}

T

$\mathrm{E}$ following information for applicants for admission to the Johns Hopkins University, printed in the University Circulars in response to letter's, we are sure will be read with interest and profit:-

How was the University Founded?-The Johns Hopkins University was instituted by the munificence of a citizen of Baltimore, Johns Hopkins, who bequeathed the most of his large estate for the establishment of a University and a Hospital. The foundation of the University is a capital, in land and stocks, estimated in value at more than $3,000,000$ dollars; the cafital of the Hospital is not less in amount. The University was incorporated under the laws of the State of Maryland, August 24, 1867, and it was opened for instruction in September, I876. The Philosophical Faculty (of Letters and Science) is now organised. A medical department will soon be instituted.

In what is Instruction Given?-Systematic instruction is offered in English, Anglo-Saxon, German, French, Italian, Spanish, Latin, Greek, Sanskrit, Hebrew, Arabic, and in other languages and literatures; in pure and applied mathematics; in chemistry (inorganic and organic) with laboratory work; in physics (including mechanics, light, heat, sound, electricity, magnetism, \&c.), with laboratory work; in biology (including physiology and morphology) with laboratory work; in mineralogy and geology ; in ancient and modern history ; in physical geography; in political economy and in the elements of international law ; in logic, ethics, psychology, pedagogics, \&c. Occasional courses of lectures are also given upon special themes in literature, science, history, archæology, art, \&c.

To whom is this Instruction offered?-To all young men who are prepared to profit by it and who will conform to the simple regulations which are established by the authorities. Graduate, Undergraduate, and Special Students are received.

Those who have not already received an academic degree, should aim to secure one by pursuing a liberal and prolonged course of study, at the close of which the degree of Bachelor of Arts will be conferred. Those who may be prevented from seeking this degree will nevertheless be welcomed to the University, provided that they are in earnest and are mature enough in years, attainments, and character to profit by the advantages which are here afforded. Others who have already taken their first degree are encouraged to go forward in advanced lines of work, and for them unusual facilities are provided. Young men who are to pursue the study of law, medicine, or theology, or who have entered upon professional lives, and others who expect to become teachers, if they desire to become proficient in literature and science, have easy access to the class-rooms and laboratories. The degree of Doctor of Philosophy may be obtained, after three years of advanced study, by those who have met the required conditions.

How is this Instruction given? - By all the methods which experience has shown to be useful-varying according to the preferences of the teachers, the subjects taught, and the number of scholars. There are recitations, lectures, conferences, prolonged courses in laboratories, exercises in special libraries, personal counsel, study of nature out of doors. The usual four-year classes are not maintained, but in all the principal subjects taught there are beginners, intermediate students, and advanced workers; so that every scholar is assigned to that position in each section of the University which will yield him the greatest advantages. He may be far advanced in one subject and only a beginner in another. This result is only secured by the engagement of a large staff of teachers.

What are the Laboratory and Library Facilities? - The scientific laboratories are three in number. They are open throughout the day and are fully equipped. For chemistry there is a special building arranged for about ninety workers, and well adapted to all kinds of chemical and mineralogical work. A large building has been recently constructed for a biological laboratory, with complete arrangements for physiological and morphological work. The physical department is furnished with apparatus selected both for demonstration and investigation, and especially valuable for researches in electricity, magnetism, light, and heat. The construction of a new building for a physical laboratory is now under way.

The library includes over 26, coo bound volumes, and 650 serials are regularly received. It is open thirteen hours daily. The library of the Peabody Institute, with 80,000 volumes, and the other Baltimore libraries, are of easy access. Washington is so near that the Library of Congress, the National Museum, and the other libraries and museums of the capital may be readily visited.

What are the Necessary Expenses of a Student? - The charge for tuition in all departments (including the use of the library, and without any extra charges except for materials consumed in the laboratories), is roo dollars per annum, payable one-half October I, and the other half February I.

Young men living in any part of Baltimore, or in the immediate vicinity, can lodge at home, as the first lessons, 
are given at 9 a.m. daily, and there is rarely any required exercise as late as 5 p.m. Young men from a distance can readily find rooms and good board either in private dwellings or in boarding houses. It is possible to secure accommodations (room and board) for 5 or 6 dollars per week, and for a sum between 6 and ro dollars per week it is still easier to be suited. The other necessary expenses of Jife are moderate.

Are there any Scholarships?-In accordance with the request of the founder of the University, twenty Hopkins scholarships, giving free tuition, are annually conferred upon matriculated undergraduate students from Maryland, Virginia, and North Carolina. In addition to these scholarships, eighteen honorary Hopkins scholarships, yielding 250 dollars and free tuition, are offered to those collegiate students from the three States above-named who pass the matriculation examinations with the most credit. Two scholarships giving free tuition are also open to matriculated students from the district of Columbia. Twenty scholarships yielding 200 dollars, and twenty fellowships yielding 500 dollars are annually open to graduate students.

What Special Opportunities are offered to University Students?-Advanced and graduate students are received with or without reference to their being candidates for a degree, and they are permitted to attend such lectures and exercises as they may select. They are not examined for admission to the University, but each instructor satisfies himself of the attainments of all who wish to follow his guidance before admitting them to his classes.

Systematic courses of instruction, varying every year, are announced in the annual programme. The professors are free to give personal counsel and instruction to those who seek it ; books and instruments adapted to investigation and advanced work have been liberally provided; the system of Fellowships secures the presence of twenty special students imbued with the University spirit, most of them looking forward to academic careers ; seminaries limited to a few advanced students under the guidance of a director have been organised in various subjects ; societies devoted to philology, to mathematical, physical, and natural science, to metaphysics, to history and political science, and to archæology, afford opportunities for the presentation of memoirs and original communications, and there are also clubs for the reading and discussion of biological, physical, and chemical papers; during the year courses of lectures are given by resident and nonresident professors on topics to which they have given special attention; the libraries of the Peabody Institute and Maryland Historical Society, founded for the advantage of scholars, are easily accessible; the issuing, under the auspices of the trustees, of publications devoted to mathematics, chemistry, philology, biology, and history brings the University into advantageous connection with other foundations; special libraries connected with the seminaries bring the most important works within easy reach of the student, and the University reading-room, which is constantly open, is liberally supplied with new and with standard books and with the literary and scientific journals of this and other lands.

On what Conditions is the Degree of Doctor of Philosophy Conferred? - The degree of Doctor of Philosophy and Master of Arts is conferred upon candidates who (after having taken their first degree) have pursued University studies, for three years, under approved conditions, have passed the required examinations and presented a satisfactory thesis. At least the last year of study must be spent in this University.

How are the Fellowships Awarded?-Twenty fellowships are annually open to competition, each yielding five hundred dollars and exempting the holder from all charges for tuition. A statement of the rules governing the awards will be sent if requested. Applications for the next year must reach the University before May I, I 886.
Is there what is commonly known as a College Course? There are seven parallel courses, by following any one of which a matriculated student may attain the degree of Bachelor of Arts. This plan combines the advantages of choice and restriction. From the variety of courses laid down, the scholar elects that which he prefers; having made his choice he finds a definite sequence of studies provided for him. The University marks out for those who elect a classical course, such a plan for the reading of Latin and Greek authors, sometimes with a teacher and sometimes privately, as will enable all who follow it to excel in these studies, while it requires that they should also learn to read French and German, and pursue during one year a course in science. It likewise provides a training which is mainly scientific, enabling the student to concentrate his attention chiefly on chemistry, or biology, or mathematics, or physics; but with these studies he must combine the study of languages, history, and philosophy.

Every matriculated student is expected to follow, under the guidance of an adviser to whom he is specially assigned, one of these prescribed courses which are fully described in the Register. Some elect the classical course. Others may concentrate their main attention upon the higher branches of mathematics. Courses are arranged also for those who wish to devote themselves chiefly to chemistry and physics. For those who expect at a later day to take up the study of medicine, there is a special course marked out, in which biology is the dominant subject. Arrangements are also made in other courses for the study of history and political science and of the modern languages and literatures.

What is required for Admission to the College Courses? - Undergraduates who wish to enter, either as matriculates, candidates for matriculation, students in the preliminary medical course, or as special students, must begin by satisfying the University that they have been thoroughly taught the English studies which are usual in good high schools, academies, and private schools, including a knowledge of arithmetic (with the metric system); geography, physical and political; the outlines of the history of the United States; English grammar and composition. The candidate for matriculation must also pass an examination in-

(I) Latin ; (2) Greek (or French and German); (3) mathematics (algebra, geometry, trigonometry, analytical geometry); (4) English ; (5) history ; (6) narural science. Those who do not intend to follow the classical course may offer French and German instead of Greek. A student may be admitted, under certain circumstances, without matriculation.

Can a Student be aided in Completing his Studies for Matriculation?--If a student at his admission passes in a considerable part of the matriculation requirements he may postpone the remainder for a time. If he is well up in algebra and geometry he may join the University classes in trigonometry and analytical geometry; if he is a good scholar in Latin and Greek, but has not read all the authors requisite for matriculation, he may receive instruction in these authors from the University ; if he has not already acquired the elements of French and German he will be aided in doing so, in order that he may enter the courses here provided.

\section{THE HARVARD PHOTOMETR $Y^{1}$}

WE have waited for the second part of this very remarkable volume completing the Harvard Photometry, rather than examine the separate portions piecemeal. There can be no doubt that its appearance is associated with an epoch in the general progress of astronomical science, coincident nearly with the other

${ }^{2}$ Constituting Parts $x$ and 2 of vol. xiv, of the Annals of the Astronomica Observatory of Harvard College. (1885.) 